\title{
Effect of some plant flavonoids on in vitro behaviour of an arbuscular mycorrhizal fungus
}

\author{
D Morandi 1, B Branzanti 2, V Gianinazzi-Pearson 1 \\ 1 INRA-CNRS, Laboratoire de Phytoparasitologie, Station de Génétique et Amélioration des Plantes, \\ INRA, BV 1540, 21034 Dijon Cedex, France; \\ 2 Universita degli Studi di Bologna, Centro di Micologia, V Filippo Re 8, 40138 Bologna, Italy
}

(COST Meeting, 21-23 May 1992, Dijon, France)

\begin{abstract}
Summary - The effect of 2 isoflavonoids (the soybean phytoalexin, glyceollin I, and the coumestan, coumestrol) and 1 flavonoid, quercetin, were tested on in vitro spore germination of Gigaspora margarita. Glyceolin I and coumestrol were tested at $0,0.05,0.5,5$ and $50 \mu \mathrm{M}$ in water agar containing $0.5 \%$ ethanol. Quercetin was tested at $0,0.1,1$ and $10 \mu \mathrm{M}$ in pure water agar. All germination parameters were measured after 5 and $7 \mathrm{~d}$. Germination rate was not significantly affected by any of these compounds. The number of germ tubes per spore was slightly increased by glyceollin I; mycelium length from germinated spores was increased by low concentrations of glyceollin I but was significantly decreased at the highest concentration. A positive correlation was found between coumestrol concentration and mycelium length, and vesicle number was decreased by coumestrol, quercetin and the highest concentration of glyceollin but was increased by glyceollin at $0.5 \mu \mathrm{M}$. Results are discussed in relation to the potential of flavonoids and isoflavonoids in acting as regulatory factors in plant-AM fungus interactions.
\end{abstract}

glyceollin I/ coumestrol / quercetin / Gigaspora margarita / in vitro culture

Résumé - Effet de la glycéolline I, du coumestrol et de la quercétine sur le comportement in vitro de Gigaspora margarita. Deux isoflavonoïdes (la glycéolline l et le coumestrol) et un flavonoide (la quercétine) ont été éprouvés vis-à-vis de la germination in vitro de Gigaspora margarita. Les expériences ont été faites en utilisant les concentrations de $0,0,05,0,5,5$ et $50 \mu \mathrm{mol} . \mathrm{t}^{-1}$ dans l'eau gélosée contenant 0,5\% d'éthanol pour les premiers et de 0,0,1, 1, et $10 \mu \mathrm{mol} . \mathrm{I}^{-1}$ dans l'eau gélosée pure pour la quercétine. Les mesures, réalisées après 5 et $7 j$ de croissance ont montré que le taux de germination n'a été affecté par aucun des composés, que le nombre de tubes germinatifs a été légèrement augmenté par la glycéolline let que la longueur du mycélium par spore germée a été augmentée par la glycéolline I aux faibles concentrations alors qu'elle a été significativement diminuée à concentration supérieure. Une corrélation positive a été trouvée entre la teneur en coumestrol et la longueur du mycélium des tubes germinatifs.

Les résultats sont discutés en relation avec la potentialité des flavonoïdes et isoflavonoïdes d'agir comme régulateurs dans le processus infectieux du champignon mycorhizien.

glycéolline I/ coumestrol / quercétine / Gigaspora margarita / culture in vitro

\section{INTRODUCTION}

Although it is not possible to culture arbuscular mycorrhizal (AM) fungi in vitro, studies on the physiology of spore germination can contribute to a better understanding of the first steps involved in the infection process leading to AM formation. Previous research on this topic suggests that molecules from the host plant are required for the expression of symbiotic fungal genes (Koske, 1982; Elias and Safir, 1987; Mosse, 1988; Bécard and Piché, 1989b; GianinazziPearson et al, 1989; Bécard and Piché, 1990;
Paula and Siquiera, 1990). In particular, the hypothesis that plant phenolics could play a role as signal molecules in plant-AM fungus interactions, as in plant-Rhizobium interactions (Firmin et al, 1986; Kosslak et al, 1987; Rolfe, 1988; Djordjevic and Weinman, 1991; Hartwig and Phillips, 1991; Hungria et al, 1991), has been investigated. The isoflavonoids formononetin and biochanin $A$, identified in clover roots, have been shown to increase AM infection in white clover (Nair et al, 1991; Siqueira et al, 1991) and the flavonoids hesperitin, naringenin and apigenin have been reported to stimulate Gigaspora margarita hyphal growth in vitro (Gianinazzi-Pearson et al, 1989), 
as has the widely occurring flavone quercetin in the presence of $\mathrm{CO}_{2}$ (Bécard et al, 1992)

Knowing that $A M$ infection can increase the accumulation of phytoalexins and associated isoflavonoids in soybean roots (Morandi et al, 1984; Morandi and Gianinazzi-Pearson, 1986; Moran$\mathrm{di}, 1989$ ) and that these compounds are generally exuded into the rhizosphere (D'Arcy-Lameta, 1984), we tested the effect of 2 soybean isoflavonoids (glyceollin I and coumestrol) and quercetin on in vitro spore germination, hyphal growth and vesicle formation of Gigaspora margarita.

\section{MATERIALS AND METHODS}

\section{Mycorrhizal fungus}

Spores of Gigaspora margarita (Becker and Hall) were collected by wet-sieving of soil from mycorrhizal Allium porrum $L$ cultures, surface sterilised and transferred to Petri dishes containing $10 \mathrm{ml}$ test media (9 spores per dish, 10 replicates per treatment) as described previously (Gianinazzi-Pearson et al, 1989).

\section{Chemicals}

Quercetin was purchased from Sigma Chemical Co. Coumestrol and glyceollin I were purified from ethanolic extracts of soybean (Amsoy 71) tissues. Coumestrol was obtained from 12-wk-old roots and glyceollin I was elicited by slicing hydrated seeds and incubating them for $48 \mathrm{~h}$ at $24^{\circ} \mathrm{C}$ in the dark. Ethanolic extracts from roots and seeds were treated by thin layer chromatography (TLC) and high performance liquid chromatography (HPLC) as described previously (Morandi, 1989). Purification of each compound was undertaken by collecting the corresponding eluate after HPLC analysis.
Different amounts of purified coumestrol and glyceollin I were dissolved in absolute ethanol from which an identical volume was added to each test medium ( $75 \%$ water agar) in order to obtain different concentrations of these compounds $(0,0.05,0.5,5$ and 50 $\mu \mathrm{M})$ with the same final ethanol concentration $(0.5 \%)$. In a preliminary experiment on glyceollin I, concentrations of $0,25,50$ and $100 \mathrm{~g} \mathrm{ml}^{-1}$ were also used. As quercetin is soluble in water, it was added directly to water agar at concentrations of $0,0.05,1$ and $10 \mu \mathrm{M}$. The solution of each test compound was sterilised using a 0.2- $\mu \mathrm{m}$ Millipore filter before mixing with autoclaved water agar.

\section{Assessment of fungal behaviour}

Percentage of germinating spores, extent of hyphal growth and number of vesicles formed were assessed as described previously (Gianinazzi-Pearson et al, 1989) after 5 and $7 \mathrm{~d}$ growth and results were statistically analysed by ANOVA and Duncan's test.

\section{RESULTS}

\section{Effect of ethanol}

Since coumestrol and glyceollin are not soluble in water and must be diluted in ethanol, it was of interest to test the effect of $0.5 \%$ ethanol on the germination of $G$ margarita spores. Results summarised in table I show that ethanol increased percentage germination, but only significantly in one experiment (glyceollin I) where spore germination was particularly low on water agar, probably due to differences in the sets of spores used. The number of germ tubes was also significantly increased by ethanol whilst length of germ tubes was significantly decreased in the experiment with coumestrol.

Table I. Effect of $0.5 \%$ ethanol on spore germination, germ tube number and length, and vesicle cluster formation of Gigaspora margarita grown in water agar for different sets of spores used in experiments testing glyceollin I and coumestrol.

\begin{tabular}{|c|c|c|c|c|c|c|c|c|}
\hline & \multicolumn{4}{|c|}{ Exp with glyceollin } & \multicolumn{4}{|c|}{ Exp with coumestrol } \\
\hline & $\mathrm{H}_{2} \mathrm{O}$ & $\begin{array}{l}d \\
E \nmid O H\end{array}$ & $\mathrm{H}_{2} \mathrm{O}$ & ${ }^{d} \mathrm{EtOH}$ & $\mathrm{H}_{2} \mathrm{O}$ & $\begin{array}{l}5 d \\
E t O H\end{array}$ & $\mathrm{H}_{2} \mathrm{O}$ & $\mathrm{EtOH}$ \\
\hline$\%$ Spores germinated & 57.5 & $84.3^{*}$ & 60.5 & 88.0 & 87.5 & 93.0 & 93.8 & 96.3 \\
\hline Germ tube number & 2.60 & $3.18^{\star}$ & 2.69 & $3.31^{*}$ & 2.84 & 3.25 & 3.60 & $4.72^{\star}$ \\
\hline Germ tube length (mm) & 2.77 & 2.39 & 4.14 & 3.51 & 3.33 & $2.32^{\star}$ & 4.67 & $3.27^{\star}$ \\
\hline Vesicles clusters/mm hypha & 0 & 0 & 0.02 & 0.07 & 0.04 & 0.07 & 0.07 & 0.11 \\
\hline
\end{tabular}

* Significant differences $(P=0.05)$ between water and ethanol results at 5 or $7 \mathrm{~d}$. 


\section{Effect of glyceollin I}

In the preliminary experiment with relatively high levels of glyceollin in the test medium, there was a clear inhibitory influence of this isoflavonoid on the germination rate of $G$ margarita (fig 1 ). Less than half of the spores germinated at the concentration of $25 \mu \mathrm{g} \mathrm{ml}^{-1}$ as compared to controls with no glyceollin. At the same time, the number of germ tubes produced increased with glyceollin concentration to nearly double at $100 \mu \mathrm{g} \mathrm{ml}^{-1}$.

In the second experiment using concentrations from 0-50 $\mu \mathrm{M}\left(16.8 \mu \mathrm{g} \mathrm{ml}^{-1}\right)$ glyceollin I (fig 2), no significant effect oh percentage germination was found but there was a tendency for this to decrease with the highest concentration $(88 \%$ germination with no glyceollin and $73 \%$ with 50 $\mu \mathrm{M}$, measured at $7 \mathrm{~d}$ ).

The number of germ tubes was significantly increased by glyceollin I (from 3.3 to 4.8 at 0 and $50 \mu \mathrm{M}$ respectively, at $7 \mathrm{~d}$ ). The number of germ tubes was considerably higher as compared to the previous experiment, where their frequency was only 1.2 per spore in the absence of glyceollin. This is again probably due to differences in the sets of spores used in the different experiments.
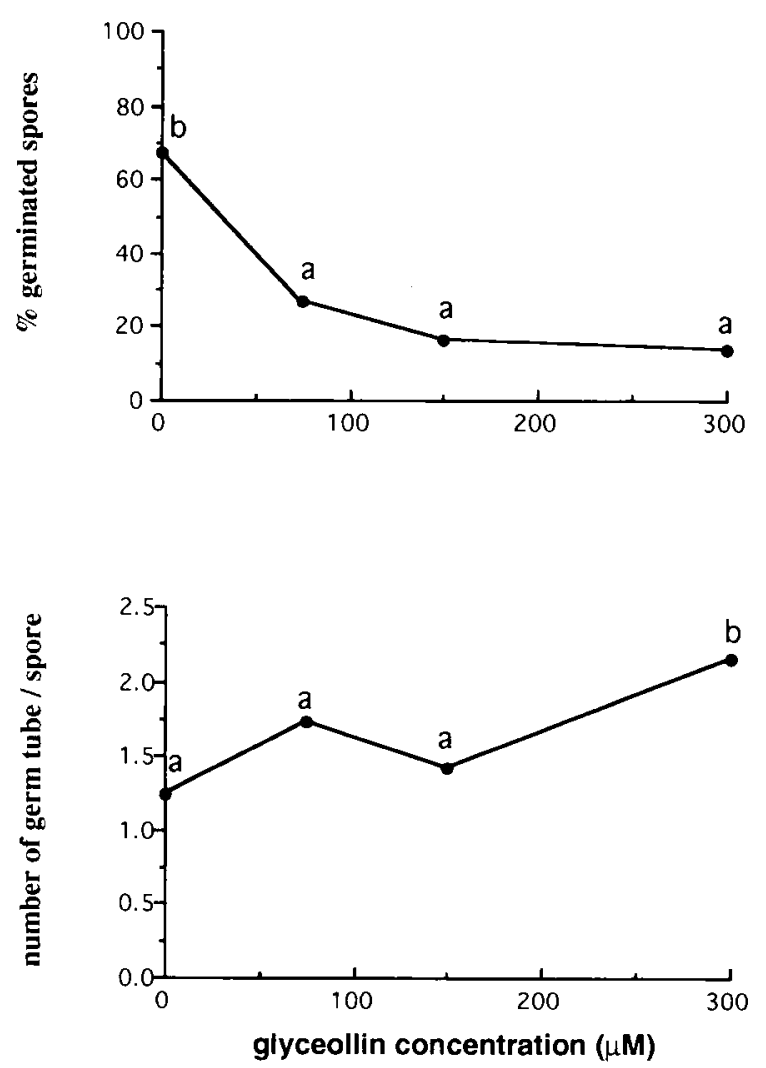

Fig 1. In vitro effect of glyceollin I on spore germination and number of germ tubes formed by Gigaspora margarita.
The length of germ tubes produced after 5 and $7 \mathrm{~d}$ was significantly affected by glyceollin: it was increased by low concentrations and decreased by the highest. At $7 \mathrm{~d}$, average germ tube length was $3.5 \mathrm{~mm}$ with no glyceollin (corresponding to a total hyphal length per spore of $12 \mathrm{~mm}), 5.8 \mathrm{~mm}$ with $0.5 \mu \mathrm{M}$ glyceollin $(22 \mathrm{~mm}$ total hyphal length) and $2.2 \mathrm{~mm}$ (11 $\mathrm{mm}$ total hyphal length) with $50 \mu \mathrm{M}$ glyceollin.

No vesicles were formed after 5 d germination, but at $7 d$, the frequency of vesicles (number hyphal length ${ }^{-1}$ ) was significantly increased by $0.5 \mu \mathrm{M}$ glyceollin and their formation was completely inhibited at the highest concentration of $50 \mu \mathrm{M}$.
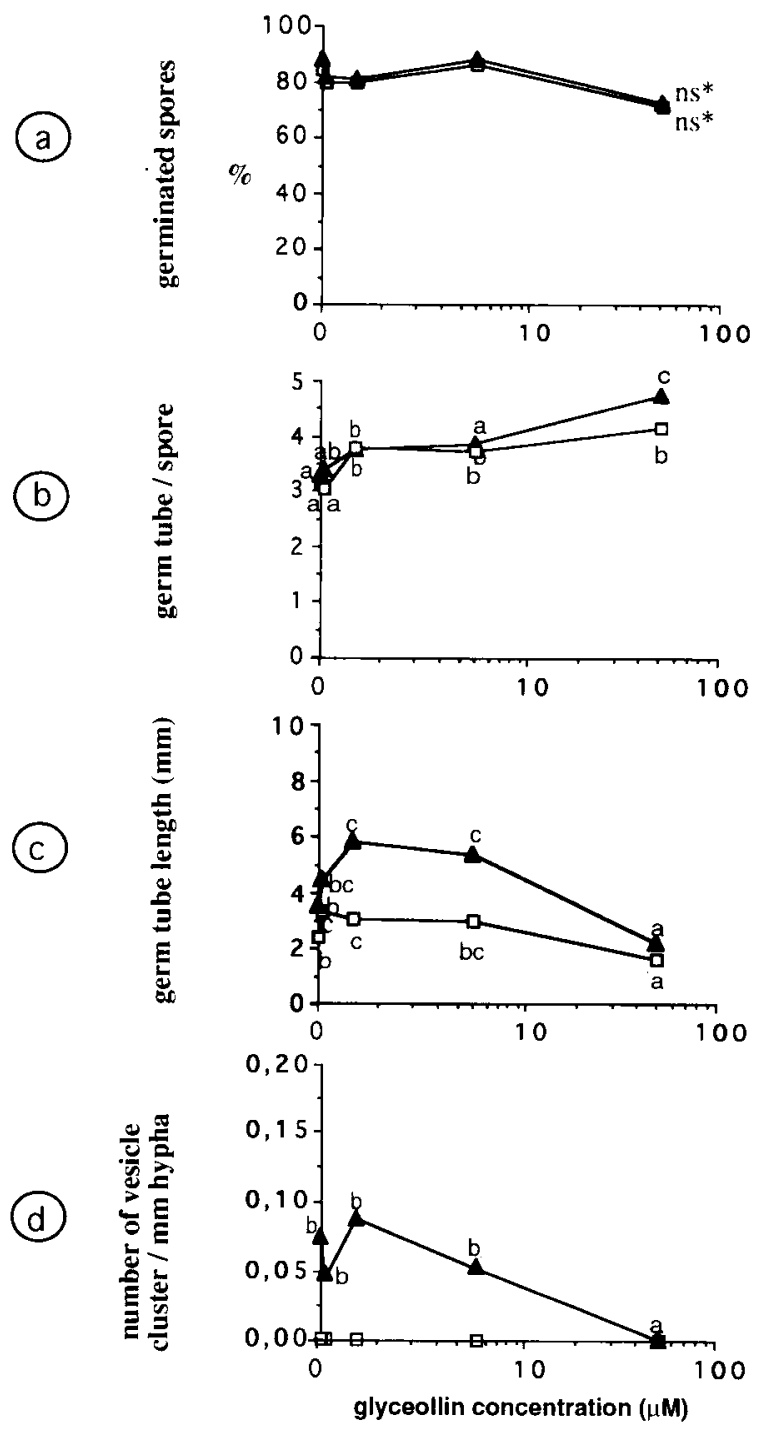

Fig 2. In vitro effect of glyceollin I on spore germination (a), number of germ tubes (b), germ tube length per spore (c) and vesicle cluster formation (d) of Gigaspora margarita after 5 ( $\square$ ) and $7(\Delta)$ d incubation. For each time $(5$ or 7 d), means associated with different letters are significantly different at $P=0.05$ (Duncan's test); " no significant difference by ANOVA at $P=0.05$. 


\section{Effect of coumestrol}

Coumestrol (fig 3) had no significant effect on percentage of spore germination or tube number per germinating spore; percentage of spore germination was very high in this experiment (already $93 \%$ after $5 \mathrm{~d}$ without coumestrol).

On the contrary, germ tube length was significantly increased by coumestrol at 5 and $7 \mathrm{~d}$. For example, at $7 \mathrm{~d}$ the average length was $3 \mathrm{~mm}$ in the absence of coumestrol $(15 \mathrm{~mm}$ total hyphal length per spore) and $7.8 \mathrm{~mm} \mathrm{(33} \mathrm{mm} \mathrm{total} \mathrm{hy-}$ phal length per spore) at a $50 \mu \mathrm{M}$ concentration. The frequency of vesicle formation was significantly reduced by the higher coumestrol concentrations.
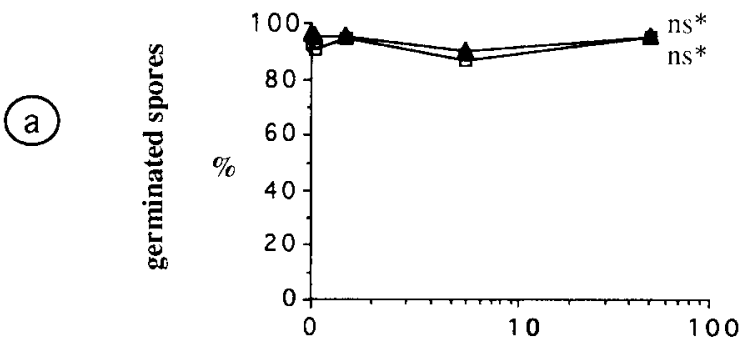

(b)
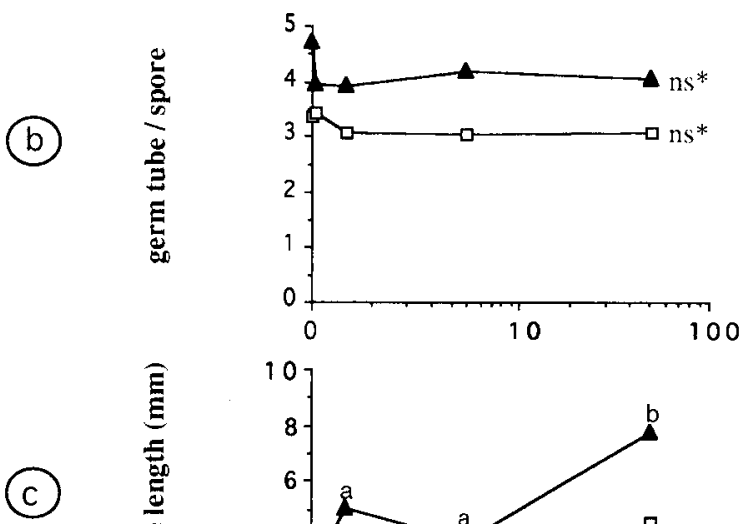

氞

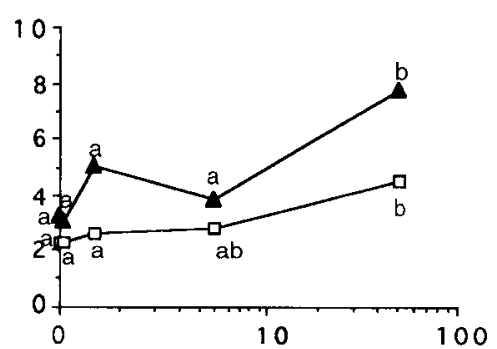

(d)

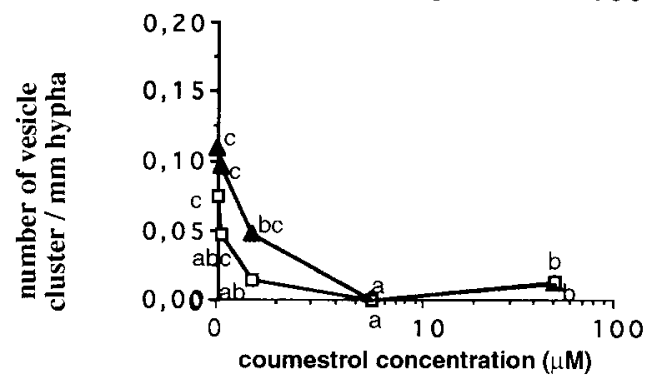

Fig 3. In vitro effect of coumestrol on spore germination (a), number of germ tubes (b), germ tube length per spore (c) and vesicle cluster formation (d) of Gigaspora margarita after $5(\square)$ and $7(\Delta) d$ incubation. For each time $(5$ or $7 \mathrm{~d})$, means associated with different letters are significantly different at $P$ $=0.05$ (Duncan's test); * no significant difference by ANOVA test at $P=0.05$.

\section{Effect of quercetin}

Quercetin (fig 4) had no significant effect on spore germination or germ tube growth but significantly decreased vesicle formation after $7 \mathrm{~d}$.

\section{DISCUSSION AND CONCLUSION}

The 3 flavonoids tested had different effects on $G$ margarita: coumestrol stimulated hyphal growth, glyceollin was inhibitory or stimulatory depending on the concentration and quercetin had no significant effect.

(a)
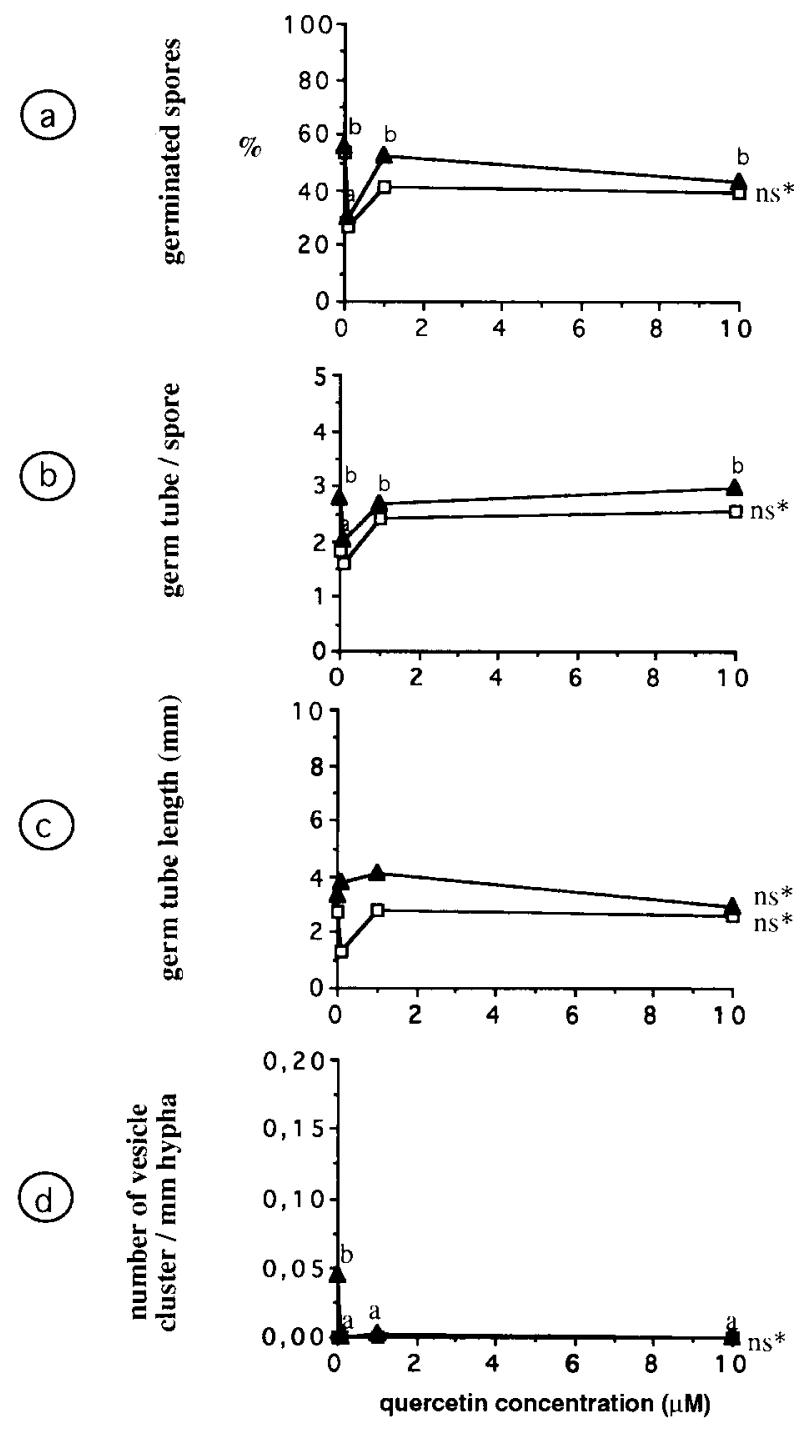

Fig 4. In vitro effect of quercetin on spore germination (a), number of germ tubes (b), germ tube length per spore (c) and vesicle cluster formation (d) of Gigaspora margarita after $5(\square)$ and $7(\Delta)$ d incubation. For each time (5 or 7 d), means associated with different letters are significantly different at $P=0.05$ (Duncan's test); " no significant difference by ANOVA test at $P=0.05$. 
Quercetin has been reported to stimulate AM fungal development, especially hyphal growth, in the case of Glomus etunicatum (Tsai and Phillips, 1991). However, in these studies, quercetin was dissolved in methanol (which is surprising since quercetin is soluble in water) and methanol concentrations in the medium varied depending on the quercetin concentration so that there was no reliable control treatment to correctly assess the effect of variable amounts of quercetin. Our present observations on the frequent stimulation of spore germination of $G$ margarita followed by a consistently toxic effect on germ tube growth by $0.5 \%$ ethanol underlines the necessity to ensure the same alcohol concentration in the medium for all the concentrations of the same test compound. Furthermore, in the studies on Glomus etunicatum (Tsai and Phillips, 1991), only very slow growth of the mycelium was observed (maximum $1 \mathrm{~mm}$ of individual hyphal length after $21 \mathrm{~d}$ ) compared to that of $G$ margarita in our experiments (a minimum of $3 \mathrm{~mm}$ after $7 \mathrm{~d}$ ). This suggests that hyphal behaviour may vary with the mycorrhizal fungus and the growth medium. Recently, Bécard et al (1992) found that quercetin stimulated hyphal growth of germinated spores of $G$ margarita, but this was in combination with $2 \% \mathrm{CO}_{2}$ which, when used independently, has been shown to increase hyphal growth (Bécard and Piché, 1989a).

The fact that glyceollin I is inhibitory to spore germination and hyphal elongation at concentrations of $\geq 50 \mu \mathrm{M}$ is not surprising because this phytoalexin has a well known fungitoxic activity, which has been demonstrated against pathogens (Giannini et al, 1990). Nevertheless, previous experiments in our laboratory have shown an accumulation of glyceollin in planta in mycorrhizal soybean roots, which can be further increased by xenobiotics without inhibiting infection development, indicating a significant tolerance of AM fungi to glyceollin. This emphasises the difference in behaviour of mycorrhizal fungi between preinfection (germination, germ tube growth) and intraradical symbiotic phases. It is also interesting to note that glyceollin I stimulated hyphal elongation at low concentrations of 0.5 and $5 \mu \mathrm{M}$, which means that this compound has differential effects on microorganisms depending on its concentration, as previously reported for pathogens (Temperli et al, 1991). Non mycorrhizal soybean roots contain $\approx 1 \mu \mathrm{g}$ glyceollin $\mathrm{g}^{-1}$ fresh mass (Morandi et al, 1984), which is equivalent to $\approx 3 \mu \mathrm{M}$ in the tissues. If we consider that a proportion of glyceollin is exuded into the rhizosphere as previously suggested (D'Arcy-Lameta, 1984; Graham,
1991), it is possible to envisage that a non mycorrhizal soybean root has a higher potential for stimulating hyphal growth from spores than a mycorrhizal one, where infection markedly increases (5-10 fold) glyceollin accumulation in root tissues (Morandi et al, 1984).

Coumestrol appears to more consistently enhance AM hyphal growth at high concentrations. This compound, which is generally present in soybean roots at high levels (100-1 $000 \mathrm{\mu g} \mathrm{g}^{-1}$ depending on plant age and mycorrhizal state) (Morandi and Gianinazzi-Pearson, 1986; Morandi, 1989), may contribute to the stimula-tory properties of host roots for AM fungal growth in situ (Elias and Safir, 1987; Gianinazzi-Pearson et al, 1989; Nair et al, 1991). The inhibitory effect of high coumestrol concentrations on vesicle cluster formation observed in the present study may also, at least partly, explain the lack of formation of these structures by $G$ margarita in root tissues.

The results obtained in the present study reinforce the hypothesis that the differential accumulation or release of certain isoflavonoids by roots may have a regulatory role in infections events in AM (Gianinazzi-Pearson et al, 1989; Nair et al, 1991; Siqueira et al, 1991; Tsai and Phillips, 1991) and that, as in legume-Rhizobium interactions, they are potential signals for activating processes essential to first steps in the infection phenomenon.

\section{REFERENCES}

Bécard G, Piché Y (1989a) Fungal growth stimulation by $\mathrm{CO}_{2}$ and root exudates in vesicular-arbuscular mycorrhizal symbiosis. App/ Environ Microbiol 55, 2620-2325

Bécard G, Piché $Y$ (1989b) New aspects on the acquisition of biotrophic status by a VAM fungus Gigaspora margarita. New Phytol 112, 77-83

Bécard G, Piché Y (1990) Physiological factors determining vesicular-arbuscular mycorrhizal formation in host and non-host $\mathrm{Ri}$ T-DNA transformed roots. Can J Bot 68, 1260-1264

Bécard G, Douds DD, Pfeffer PE (1992) Extensive in vitro hyphal growth of vesicular-arbuscular mycorrhizal fungi in the presence of $\mathrm{CO}_{2}$ and flavonols. Appl Environ Microbiol 58, 821-825

Djordjevic MA, Weinman JJ (1991) Factors determining host recognition in the clover-Rhizobium symbiosis. Aust J Plant Physiol 18, 543-557

Elias KS, Safir GR (1987) Hyphal elongation of Glomus fasciculatum in response to root exudates. Appl Environ Microbiol 53, 1928-1933 
Firmin JL, Wilkison KE, Rossen L, Johnston AWB (1986) Flavonoid activation of nodulation genes in Rhizobium reversed by other compounds present in plants. Nature 324, 90-91

Gianinazzi-Pearson V, Branzanti B, Gianinazzi S (1989) In vitro enhancement of spore germination and early hyphal growth of a vesicular-arbuscular mycorrhizal fungus by root exudates and plant flavonoids. Symbiosis 7, 243-255

Giannini JL, Holt JS, Briskin DP (1990) The effect of glyceollin on proton leakage in Phytophthora megasperma F-sp glycinea plasma membrane and red beet tonoplast vesicles. Plant Sci $68,39-45$

Graham TL (1991) Flavonoid and isoflavonoid distribution in developing soybean seedling tissues and in seed and root exudates. Plant Physio/ 95, 594-603

Hartwig UA, Phillips DA (1991) Release and modification of nod-gene-inducing flavonoids from alfalfa seeds. Plant Physiol 95, 804-807

Hungria M, Joseph CM, Phillips DA (1991) Rhizobium nod gene inducers exuded naturally from roots of common bean (Phaseolus vulgaris L). Plant Physiol 97, 759-764

Koske RE (1982) Evidence for a volatile attractant from plant roots affecting germ tubes of a VA mycorrhizal fungus. Trans Br Mycol Soc 79, 305-310

Kosslak RM, Bookland R, Barkei J, Paaren HE, Appelbaum ER (1987) Induction of Bradyrhizobium japonicum common nod genes by isoflavones isolated from Glycine max. Proc Natl Acad Sci USA 84, 7428-7432

Morandi D (1989) Effect of xenobiotics on endomycorrhizal infection and isoflavonoid accumulation in soybean roots. Plant Physiol Biochem 27, 697-701

Morandi D, Bailey JA, Gianinazzi-Pearson V (1984) Isoflavonoid accumulation in soybean roots infect- ed with vesicular-arbuscular mycorrhizal fungi. Physiol Plant Pathol 24, 357-364

Morandi D, Gianinazzi-Pearson V (1986) Influence of mycorrhizal infection and phosphate nutrition on secondary metabolite contents of soybean roots. In: Physiological and Genetical Aspects of Mycorrhizae (V Gianinazzi-Pearsons, S Gianinazzi, eds) INRA Press, Paris

Mosse B (1988) Some studies related to "independent" growth of vesicular-arbuscular endophytes. Can J Bot 66, 2533-2540

Nair MG, Safir GR, Siqueira JO (1991) Isolation and identification of vesicular-arbuscular mycorrhizastimulatory compounds from clover (Trifolium repens) roots. Appl Environ Microbiol 57, 434-439

Paula MA, Siquiera JO (1990) Stimulation of hyphal growth of the VA mycorrhizal fungus Gigaspora margarita by suspension cultured Pueraria phaseolides cells and cell products. New Phytol 115, 6975

Rolfe BG (1988) Flavones and isoflavones as inducing substances of legume nodulation. Biofactors 1, 310

Siqueira JO, Safir GR, Nair MG (1991) Stimulation of vesicular-arbuscular mycorrhiza formation and growth of white clover by flavonoid compounds. New Phytol 118, 87-93

Temperli E, Roos UP, Hohl HR (1991) Germ tube growth and the microtubule cytoskeleton in Phytophthora infestans. Effects of antagonists of hyphal growth, microtubule inhibitors, and ionophores. $M y$ col Res 95, 611-617

Tsai SM, Phillips DA (1991) Flavonoids released naturally from alfalfa promote development of symbiotic Glomus spores in vitro. Appl Environ Microbiol 57, $1485-1488$ 